\title{
Vascular Anomalies (Part II): Interventional Therapy of Peripheral Vascular Malformations
}

\section{Gefäßanomalien (Teil II): Interventionelle Therapie von peripheren Gefäßmalformationen}

Authors

René Müller-Wille', Moritz Wildgruber ${ }^{2}$, Maliha Sadick ${ }^{3}$, Walter A. Wohlgemuth ${ }^{4}$

Affiliations

1 Institute for Diagnostic and Interventional Radiology, Georg-August-Universität Göttingen, Universitätsmedizin, Göttingen, Germany

2 Department for Clinical Radiology, Westfälische Wilhelms Universität Münster, Medizinische Fakultät, Münster, Germany

3 University Medical Center Mannhein, Institute for Clinical Radiology and Nuclear Medicine, Mannheim, Germany

4 Department for Radiology, Martin-Luther-Universität Halle-Wittenberg, Halle, Germany

Key words

vascular anomalies, vascular malformations, angiography, embolization, sclerotherapy

received 18.12.2017

accepted 10.01.2018

Bibliography

DOI https://doi.org/10.1055/s-0044-101266

Published online: 7.2.2018

Fortschr Röntgenstr 2018; 190: 927-937

(c) Georg Thieme Verlag KG, Stuttgart · New York ISSN 1438-9029

Correspondence

Prof. Dr. Moritz Wildgruber

Institut für Klinische Radiologie, Technische Universität

München, Albert-Schweitzer-Campus 1, 48149 Münster, Germany

Tel.: +49/2 51/8344381

moritz.wildgruber@ukmuenster.de

\section{ZUSAMMENFASSUNG}

Hintergrund Die International Society for the Study of Vascular Anomalies (ISSVA) teilt vaskuläre Anomalien in vaskuläre Tumoren und vaskuläre Malformationen ein. Letztere werden weiter in Läsionen mit langsamen Fluss (venöse, lymphatische und kapilläre Malformationen) und Malformationen mit schnellem Fluss (arteriovenöse Malformationen und Fisteln) unterteilt. Diese interdisziplinär akzeptierte Klassifikation hat Auswirkungen auf die Wahl der Therapie.
Methodik In diesem Artikel werden basierend auf der aktuellen Literatur die wichtigsten Informationen über Terminologie und Behandlungsstrategien peripherer Gefäßmalformationen präsentiert. Hierbei liegt der Fokus auf der interventionellen Behandlung von venösen Malformationen (VM), lymphatischen Malformationen (LM), arteriovenösen Malformationen (AVM) und arteriovenösen Fisteln (AVF).

Ergebnisse und Schlussfolgerung Eine korrekte Klassifizierung ist essentiell für die adäquate Behandlung von peripheren vaskulären Malformationen. Moderne Bildgebung und dedizierte interventionelle Methoden sind ein zentraler Teil der multidisziplinären Behandlung von Gefäßmalformationen. Malformationen mit langsamem Fluss können erfolgreich sklerosiert, Malformationen mit schnellem Fluss kurativ embolisiert werden.

\section{Kernaussagen:}

- Die ISSVA Klassifikation ist entscheiden für die korrekte Diagnose und Einteilung von Gefäßmalformationen

- Die Schobinger Klassifikation sowie die Cho Klassifikation sollten für die Beschreibung von arteriovenösen Malformationen (AVM) verwendet werden

- Sklerotherapie und Embolisation sind die Verfahren der ersten Wahl zur Behandlung von Gefäßmalformationen

\section{ABSTRACT}

Background The International Society for the Study of Vascular Anomalies (ISSVA) categorizes vascular anomalies into vascular tumors and vascular malformations. Vascular malformations are further divided into slow-flow (venous, lymphatic, and capillary malformation) and fast-flow malformations (arteriovenous malformation and arteriovenous fistula). This interdisciplinary classification has therapeutic implications. Methods The objective of this article is to provide concise information about the current terminology and treatment strategies of peripheral vascular malformations, based on the currently available literature, with a focus on interventional therapy of venous malformations (VM), lymphatic malformations (LM), arteriovenous malformations (AVM) and arteriovenous fistulae (AVF). Results and Conclusion Accurate classification is crucial for appropriate therapy of peripheral vascular malformations. Modern imaging technologies and refined interventional treatment strategies are now central parts in the multidisciplinary management of these patients. Slow-flow and fast- 
flow vascular malformations can be treated successfully by percutaneous sclerotherapy and endovascular embolotherapy as first-line interventions.

Key points:

- The ISSVA classification is essential for the correct diagnosis of vascular malformations

- The Schobinger classification as well as the Cho classification should be used for description of arteriovenous malformations (AVM)
- Sclerotherapy and embolotherapy are the primary treatments of choice for vascular malformations

\section{Citation Format}

- Müller-Wille R, Wildgruber M, Sadick M et al. Vascular Anomalies (Part II): Interventional Therapy of Peripheral Vascular Malformations. Fortschr Röntgenstr 2018; 190: 927-937

\section{Introduction}

Based on the landmark article of Mulliken and Glowacki [1], the International Society for the Study of Vascular Anomalies (ISSVA) categorizes vascular anomalies into vascular tumors and vascular malformations [2]. Vascular malformations are further divided into slow-flow (venous, lymphatic, and capillary malformation) and fast-flow malformations (arteriovenous malformation and arteriovenous fistula) [2] ( up to now there has been a lack of familiarity with this interdisciplinary classification system $[3,4]$. Furthermore, when asked how to manage peripheral vascular malformations, we are faced with a large number of studies and case series with low levels of evidence and mixed results, which in the face of individual varying patient presentations makes it nearly impossible to decide what the optimal treatment strategy for each patient is. It is generally recommended that the treatment of peripheral vascular malformations has to be performed in a multidisciplinary setting. Especially the radiologist plays an important role in the diagnosis and interventional management of patients with peripheral vascular malformations. However, this necessitates knowledge not just about technical aspects of percutaneous sclerotherapy or embolization, but also about medical treatment options, anticoagulation, and compression garments. It is self-evident that all this requires close communication between the patient, the radiologist and other specialists.

The objective of this article is to provide the most important information about the current terminology and interventional treatment strategies of slow-flow and fast-flow peripheral malformations, based on the currently available literature.

\section{Pre-interventional work-up}

Accurate diagnosis using appropriate terminology is crucial for appropriate therapy of congenital peripheral vascular malformations. The physical examination focuses in particular on skin changes, overgrowth, mobility disorders, pulsations and complications, like necrosis or ulcerations. The physical examination should be supplemented by a medical history that includes quality-of-life, coagulopathies, thrombosis, thromboembolism, bleeding, infections, allergies, congenital heart defects, pregnancy and family history. Ultrasound is widely available and should be performed in every patient. To determine the exact extent of the mal- formation and for treatment planning, a baseline contrastenhanced magnetic resonance imaging (MRI) examination including dynamic MR-angiography is reasonable in most patients.

The decision for invasive treatment should be made by an interdisciplinary team and is based on individual symptoms and possible complications of the natural course of the disease. The risks of the invasive procedure have to be weighed against the potential benefits. The patient should be informed about the exact procedure, all alternative methods, and specific risks of the intervention as well as the need for subsequent interventional procedures, as malformation treatment is rarely completed within a single session. Treatment goals should be explicitly stated before the intervention.

Pre-interventional laboratory tests include serum creatinine, thyroid hormones, complete blood count, clotting parameters, fibrinogen, and d-dimers. Based on the patient's age, location of the malformation and type of intervention, the patient is placed under conscious sedation or general anesthesia. Strict monitoring of vital signs and a local sterile drape are imperative. Digital subtraction angiography (DSA), "road map" or "overlay" capabilities should be available for complex interventions. Biplane angiography is beneficial especially in pediatric patients with restrictions in contrast dose.

\section{Therapy of slow-flow malformations}

\section{Therapy of venous malformations (VMs)}

\section{Brief description}

Venous malformations (VMs) are the most common vascular malformations. VMs are composed of dilated, sponge-like venous channels of variable size. Histologically, they have abnormally developed vein walls with defects in the smooth muscle layer and an absence of valves. This makes them difficult to puncture and prone to easy rupture by injections or needle movements. They are present at birth and can occur in any anatomic site or tissue, like skin, muscle, bone, or viscera. In general, they are welldefined and localized, but can also have a more diffuse and infiltrating appearance, e.g. involving all tissue layers of one extremity. They may be associated with other clinical conditions like Klippel-Trenaunay syndrome (KTS) [5, 6]. VMs grow proportionately to the surrounding tissue, but enlargement can occur properly due to continuous stretching of the abnormal vein wall, surgi- 
- Table 1 ISSVA classification of vascular anomalies.

- Tab. 1 ISSVA-Klassifikation von Gefäßanomalien.

vascular anomalies

vascular tumors

vascular malformations

- benign

- locally aggressive

or borderline

- malignant

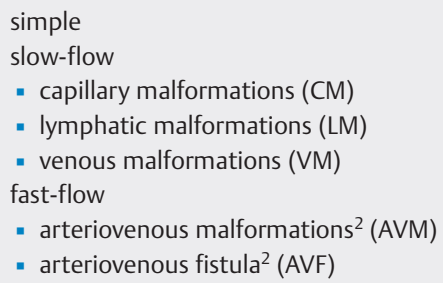

$$
\begin{aligned}
& \text { combined }^{1} \\
& \text { - CVM } \\
& \text { - CLM } \\
& \text { - LVM } \\
& \text { - CLVM } \\
& \text { - CAVM }{ }^{2} \\
& \text { - CLAVM }{ }^{2} \\
& \text { - Others }
\end{aligned}
$$

cal resection, biopsy, trauma, infections, or under hormonal influences (puberty or pregnancy).

The clinical manifestations vary, depending on the extent and site of the VM. Superficial VMs appear as a soft, bluish, non-pulsatile, and compressible mass. They typically increase in size during Valsalva maneuver. Most VMs become symptomatic due to stagnation of blood and localized thrombosis/thrombolysis. Large VMs are often associated with localized intravascular coagulopathy (LIC), a consumptive coagulopathy characterized by elevated D-dimer and decreased fibrinogen levels [7 - 10]. Persistent calcified clots, so called phleboliths, are pathognomonic findings ( $\triangleright$ Fig. 1a). VMs can at the same time cause disfigurement or impairment of neighboring structures and organs (e.g. obstruction of airways). Hemorrhage is generally uncommon. However, recurrent synovial bleeding may lead to hemosiderin arthropathy [11]. In sum, many patients with VMs suffer from bodily pain with overall reduced physical function [12].

Most VMs can be diagnosed based upon medical history and physical examination. However, ultrasound and MRI ( $\triangleright$ Fig. 1a) are needed for complete pre-interventional assessment and follow-up after invasive therapy [13-15].

\section{Conservative management}

Conservative management of VMs includes the prescription of individually adjusted compression garments. Appropriately fitted compression garments can reduce pain, slow progression, and deformity [16]. Paroxysmal pain secondary to intralesional localized thrombosis can be managed with generally available pain-relieving agents. In addition, low-molecular-weight heparin (LMWH) can be used to prevent ongoing clotting. Prophylactic LMWH is also indicated during high thrombosis risk states and in conjunction with invasive therapy. Some authors recommend the use of LMWH in patients with LIC prior to sclerotherapy to normalize the fibrinogen level $[9,15]$. Recurrent thromboembolic events are reasons for long-term anticoagulation and interventional or surgical disruption of communications between the VM and central draining veins. Occasionally, cessation of oral contraceptives could be considered [16]. Unfortunately, direct medical treatment of VMs has been quite limited until now. Promising small case series showed that mTOR inhibitors (sirolimus) seem to have a positive clinical effect on VMs [17-21]. Nevertheless, long-term effects are unclear and controlled studies are still missing.

\section{Sclerotherapy}

Invasive therapy is indicated in conjunction with conservative management in symptomatic VMs to reduce pain, disfigurement, hemorrhage, and impairment of neighboring structures or to reduce the thromboembolic risk. Percutaneous sclerotherapy is the first-choice invasive treatment method and can be combined with additional laser therapy or surgical procedures [22]. However, evidence is low and the choice for the invasive method remains a shared decision between the patient and a multidisciplinary team of specialists $[22,23]$.

The aim of sclerotherapy is to damage the endothelial lining of the $\mathrm{VM}$, resulting in thrombosis, inflammation, and subsequent fibrosis of the abnormal vein channels with a reduction of the size [24]. A variety of sclerosants are available that differ in their mode of action. Frequently used sclerosants for VMs are ethanol, ethanol gel, polidocanol, sodium tetradecyl sulfate, and bleomycin. Systematic reviews could not identify a significantly superior sclerosing agent in terms of effectiveness [23, 25-27]. Instead, it is vital to consider the local and systemic side effects of the different sclerosing agents.

- Ethanol: Highly concentrated ethanol is a very effective sclerosant for the treatment of VMs [28-31]. It causes precipitation of endothelial cells and thrombosis. Nonetheless, absolute ethanol can result in serious local and systemic side effects like compartment compression, necrosis, ulcer, hyperpigmentation, nerve injury, hypoglycemia, deep vein thrombosis, pulmonary thrombosis, pulmonary vasospasm, cardiac collapse, and death [29-34]. It has been shown that ethanol has a significantly higher complication rate compared to other sclerosants $[25,32,35]$. Therefore, it should be used only by experi- 


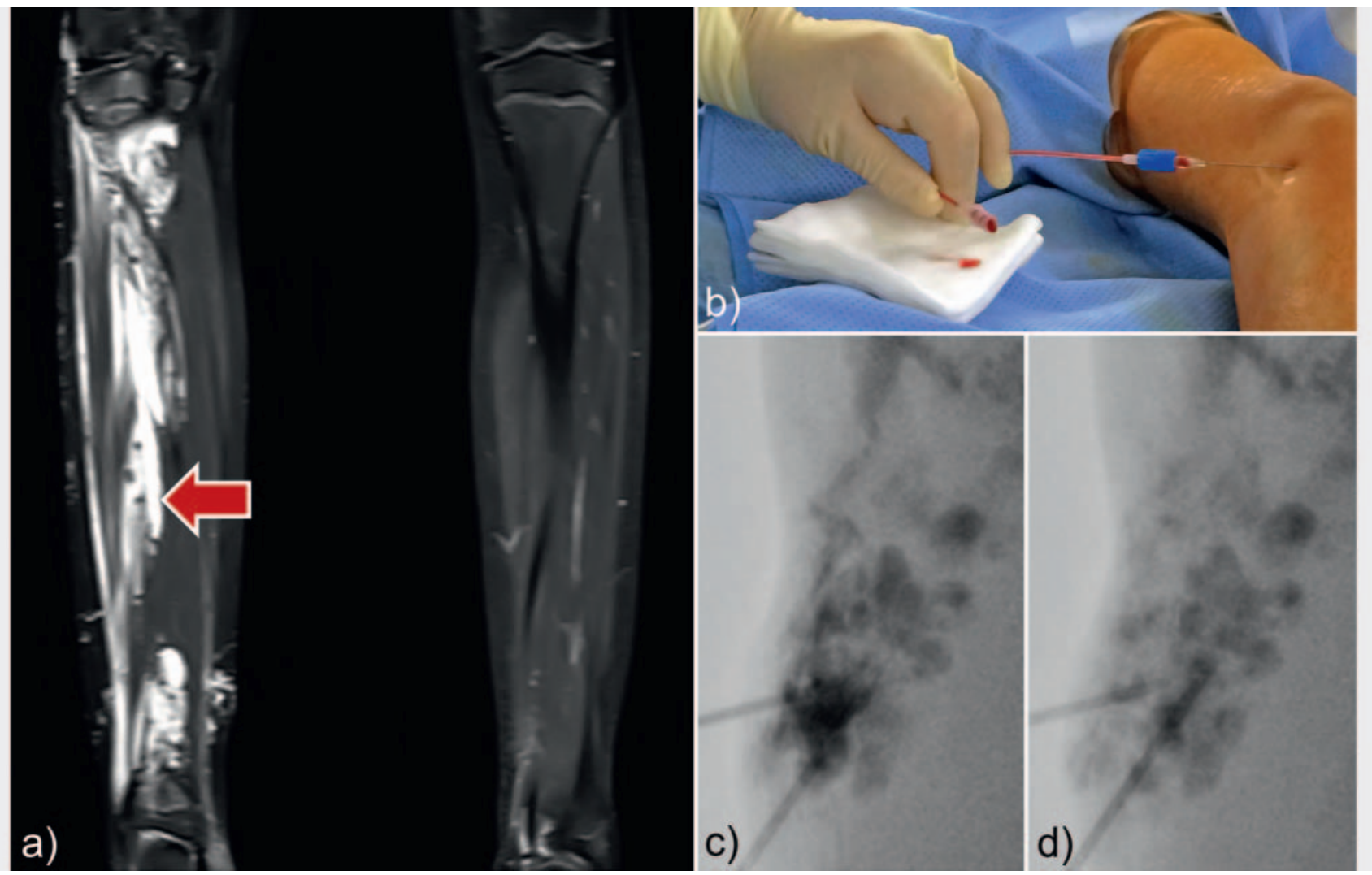

- Fig. 1 Venous malformation a STIR sequence showed a hyperintense venous malformation with central phleboliths (arrow) b Percutaneous puncture of the venous malformation $\mathbf{c}$ Injection of contrast media into the venous malformation $\mathbf{d}$ Injection of Polidocanol foam.

- Abb. 1 Venöse Malformation a Hyperintense venöse Malformation mit zentralen Phlebolithen in der STIR Sequenz (Pfeil) b Perkutane Punktion der venösen Malformation c Injektion von Kontrastmittel in die venöse Malformation d Injektion von Polidocanol-Schaum.

enced interventional radiologists. One study showed that the total dose of $0.2 \mathrm{ml}$ per $\mathrm{kg}$ appears to be the threshold to reduce side effects [36]. Ethanol can be mixed with lipiodol for radiopacity.

- Ethanol gel: To limit diffusion and to keep ethanol in the malformation, it can be administrated in highly viscous gel form. Ethanol gel has a favorable safety profile in the treatment of VMs compared to pure ethanol [37-40]. A recent published prospective study showed that restrictions in bodily pain and general health are successfully returning to normal levels in patients with VMs after sclerotherapy with ethanol gel [12].

- Polidocanol: Polidocanol is a local anesthetic also used as a sclerosant for VMs with fewer side effects than absolute ethanol $[25,41-43]$. There is some evidence that polidocanol foam, made by mixing polidocanol with sterile air (Tessari technique [44]), has a higher rate of obliteration compared to the application of liquid polidocanol [45] ( $\triangleright$ Fig. 2).

- Sodium tetradecyl sulfate (STS): STS is the active component of the sclerosant drug Sotradecol. It has been demonstrated that STS foam is an effective sclerosing agent for VMs with a low complication risk [46, 47].

- Bleomycin: Bleomycin is a cytotoxic, antineoplastic antibiotic derived from Streptomyces verticillus. The sclerosing effect of bleomycin on the vessel endothelium can be used for the treatment of VMs [32, 35, 48]. Post-procedural swelling is less intensive after bleomycin application compared to ethanol [35]. These properties made bleomycin the sclerosant of choice in patients with airway compression. However, there is a potential risk of pulmonary fibrosis after bleomycin admission. Therefore, bleomycin must be used in a very small dose with no more than $1 \mathrm{mg} / \mathrm{kg}$ body weight per session [16]. Bleomycin may induce neoplasms, thus its use in children is to be considered with special caution.

Application techniques: Direct needle puncture of the VM is performed with a 20- or 21-gauge needle under real-time ultrasound guidance. Accidental puncture of neurovascular structures should be avoided. The needle is connected to a $10 \mathrm{ml}$ syringe of saline and is gradually withdrawn while applying low suction. As soon as blood returns, a radiopaque contrast agent is injected to obtain a phlebogram of the VM to confirm the position, estimate the lesion volume and compartmentalization and to identify draining veins. Four different phlebographic patterns of VMs can be observed [49] ( $\triangleright$ Fig. 3). Type I lesions are VMs without considerable venous drainage under fluoroscopy. Type II and III VMs have normal-sized and enlarged venous drainage, respectively. Type IV lesions are composed of basically ectatic dysplastic vein. VMs with 


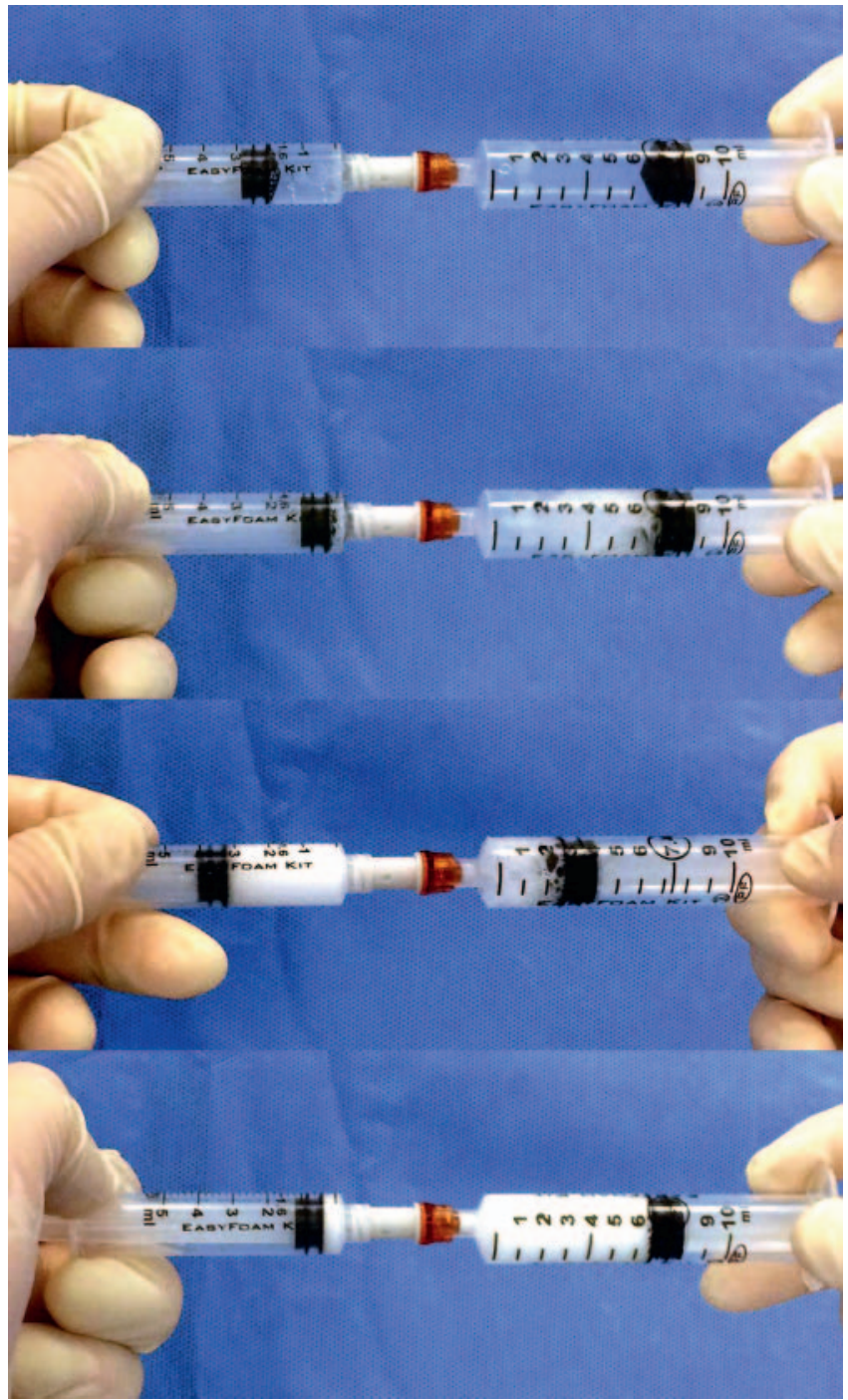

- Fig. 2 Polidocanol foam. Preparation of Aethoxysklerol foam.

- Abb. 2 Polidocanol-Schaum. Präparation von PolidocanolSchaum.

large draining veins suggest a higher risk of complications during sclerotherapy [49].

After identification of the phlebographic patterns, the sclerosant can be injected slowly under fluoroscopy to displace the previously injected contrast agent residing in the malformation. A tourniquet or a pneumatic cuff at the venous outflow minimizes the risk of accidental migration into the deep venous system. Additionally, local compression of visible draining veins may be considered. In some cases it is necessary to puncture the VM more than once to treat the lesion completely. However, injection has to be stopped if there is increased resistance, extravasation of the sclerosant, or skin blanching.

\section{Additional venous outflow occlusion}

In cases with large draining veins, additional occlusion may be indicated to avoid overflow of the sclerosing agent into the deep vein system [50]. Fibered microcoils or plugs of various types can be placed through an access needle or a catheter into the outflow vessel of the VM.

\section{Endovenous ablation techniques}

Endovenous ablation techniques like endovenous laser ablation (ELVA) or endovenous radiofrequency ablation (ERFA) were successfully used to close large embryonic venous channels such as the lateral marginal vein in patients with KTS [51, 52]. It is recommended that patients presenting with such anomalous veins be considered for endovenous ablation therapy as early as possible to reduce the risk of thromboembolism [52].

\section{Post-procedural care}

Patients should wear their compression garments to help involution of the lesion. Limb elevation, ice packs, and pain medication (an NSAID is normally sufficient) may be indicated. To prevent deep vein thrombosis (DVT), we recommend prophylactic anticoagulation with LMWH. Ultrasound should be performed to exclude DVT one day after therapy of limb VMs.

\section{Therapy of lymphatic malformations (LMs)}

\section{Brief description}

Lymphatic malformations (LMs) are the second most common type of peripheral vascular malformation. LMs are congenital lesions of the lymphatic system and consist of cystic spaces filled with lymphatic fluid and dilated lymphatic channels. Although there are multiple definitions, LMs are classified as microcystic, macrocystic (>1 cm), and mixed [2]. Chanel type LMs are characterized by dilatation and insufficiency of lymphatic canals. LMs are most commonly located in the head and neck area, followed by the axilla and pelvis $[15,53]$. Cystic LMs present as a focal mass or diffuse swelling. Compression of the upper airways is possible. In contrast to VMs, LMs do not expand with the Valsalva maneuver. LMs grow proportionately to the body, but enlargement can occur during adolescence. Acute increase can occur due to intracystic hemorrhage or infection. Cutaneous LMs present as vesicles, which may leak clear or bloody fluid.

After birth, LM diagnosis is generally determined by medical history and physical examination. In addition, ultrasound and MRI are able to demonstrate the extent of the LM ( $\bullet$ Fig. 4a).

\section{Medical therapy}

Small asymptomatic LMs can be monitored without immediate treatment. Antibiotic medications are indicated to prevent and treat infections of LMs. Recent studies demonstrated that mTOR inhibitors (sirolimus) had a positive clinical effect on extensive LMs especially in infants with cervicofacial lesions $[18,54,55]$. In one study with 19 patients, no opportunistic or systemic bacterial infection occurred [54]. However, long-term results and controlled studies are still missing.

\section{Sclerotherapy}

Indications for invasive therapy of LMs are usually recurrent infection, recurrent hemorrhage, impairment of neighboring struc- 


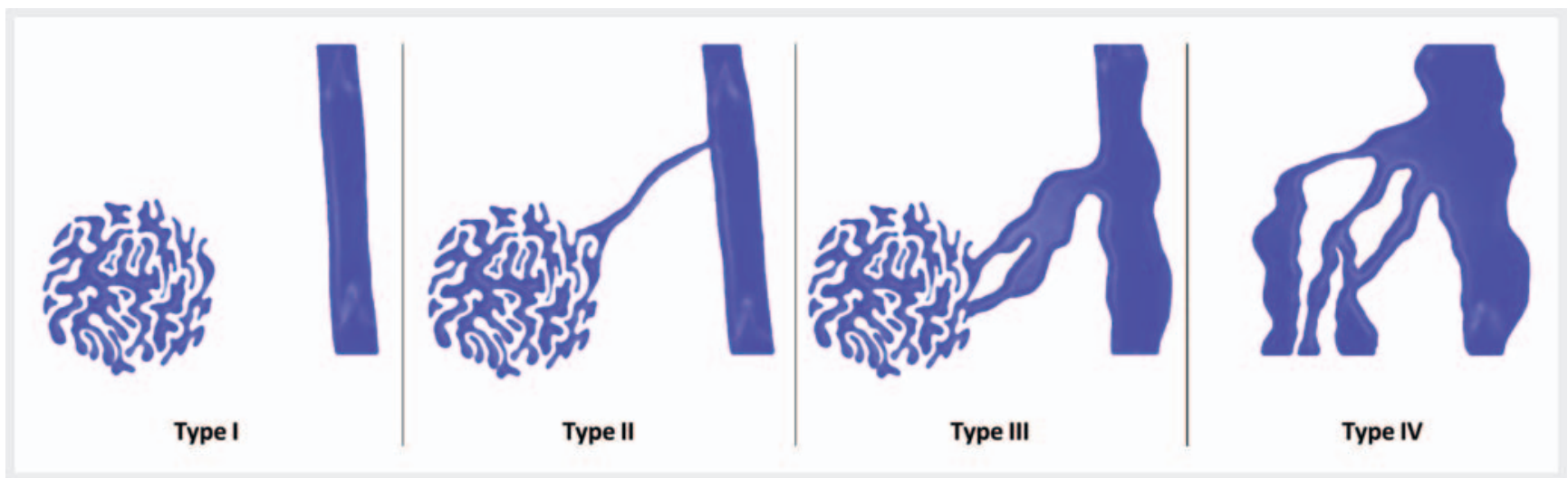

- Fig. 3 Classification of venous malformations. Type I lesions are isolated malformations without phlebographically visible venous drainage. Type II and III lesions demonstrate normal-sized and enlarged venous drainage, respectively. Type IV lesions are composed of essentially ectatic dysplastic veins.

- Abb. 3 Klassifikation der venösen Malformation. Typ 1 Läsionen sind isolierte Malformationen ohne phlebographisch sichtbare Drainagevenen. Typ II und III Läsionen zeigen normalgroße oder erweiterte Drainagevenen. Typ IV Läsionen bestehen aus ekstatischen, dysplastischen Venen.

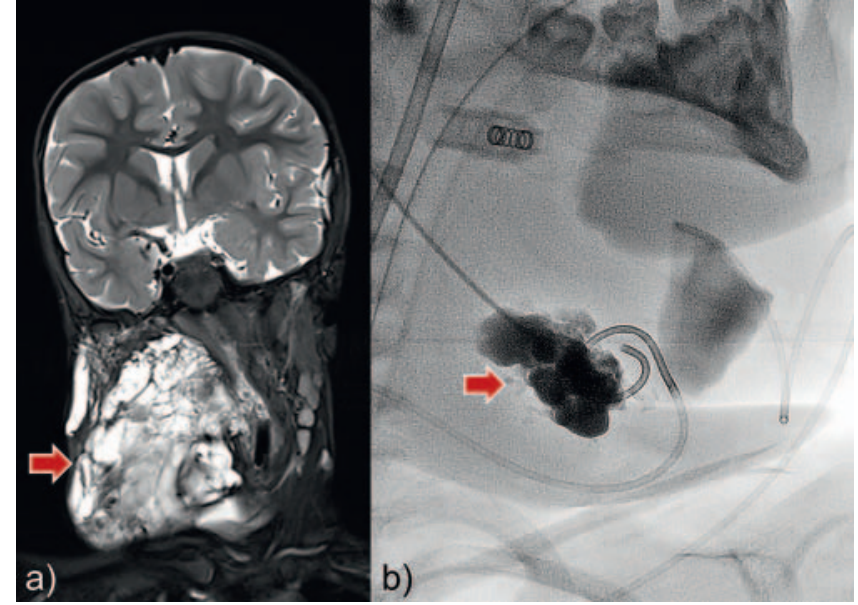

- Fig. 4 Macrocystic lymphatic malformation. a STIR sequence presented a hyperintense macrocystic lymphatic malformation of the neck (arrow) b Two 3-French pigtail catheters were inserted into the cysts and contrast media was injected before sclerotherapy with OK-432 (arrow).

- Abb. 4 Makrozystische lymphatische Malformation a In der STIR Sequenz zeigt sich eine hyperintense makrozystische lymphatische Malformation des Halses (Pfeil). b Platzierung zweier 3-French Pigtail-Katheter in die Zysten und Injektion von Kontrastmittel vor Injektion des Sklerosierungsmittels OK-432 (Pfeil).

tures (e.g. upper airways), and disfigurement [53]. Historically, LMs were resected surgically with the risk of incomplete resection and functional or cosmetic side effects. It has been demonstrated that percutaneous sclerotherapy is very effective in reducing the size and symptoms of macrocytic lesions with a low risk for adverse events. However, microcystic LM lesions respond less to percutaneous sclerotherapy [53]. The most commonly used sclerosants are Picibanil (OK-432), Bleomycin, and Doxycycline. STS seems to be less effective [56] and injection of ethanol carries the risk of increased complications [53].
- Picibanil (OK-432): Picibanil is a lyophilized mixture of group A Streptococcus pyogenes with a high capacity to produce fibrosis. Intracystic injection of Picibanil has been shown to be an effective and safe treatment for macrocystic LMs in children $[31,57,58]$. Repeated injections are often required to achieve clinical success [58]. It must be mentioned that Picibanil can induce severe swelling for more than one week after treatment [59]. In cases with potential airway compression, elective intubation and ventilation following sclerotherapy may be necessary [59]. Another typical side effect of Picibanil is post-procedural fever. It can be successfully treated with paracetamol and resolves after 1 - 3 days [57].

- Bleomycin: The sclerosing effect of bleomycin has been well known for over forty years [60]. Due to its low risk of swelling, it is a preferred agent in patients with macrocystic LMs of the head and neck area [61]. As mentioned above, bleomycin must be used in very small doses to avoid side effects like pulmonary fibrosis [16].

- Doxycycline: Doxycycline is very effective for the treatment of macrocystic and mixed head and neck lymphatic malformations in children [56, 58, 62-64]. Positive effects are often seen after a single session [56, 58, 62]. It has minimal side effects and is widely available [62].

Application techniques: Cysts are cannulated with a needle under real-time ultrasound guidance. Alternatively, a pigtail catheter ( 3 to 5 French) can be inserted in larger cysts, as the multiple side holes facilitate aspiration of the lymphatic fluid before injection of the sclerosing agent ( $\triangleright$ Fig. $\mathbf{4 b}$ ). Contrast media can be injected to visualize the whole lesion under fluoroscopy. After aspiration of the entire cyst content, the LM can then be treated with the sclerosant.

\section{Post-procedural care}

Strict postoperative observation of the upper airway is recommended after treatment of patients with large cervical LMs [59]. 
Fever after injection of Picibanil can be treated with paracetamol. The positive effect of sclerotherapy is not visible immediately, but after $4-6$ weeks.

\section{Therapy of fast-flow vascular malforma- tions (AVMs and AFs)}

\section{Brief description}

Fast-flow vascular malformations are defined as abnormal shunts between arteries and veins without an intervening capillary bed [65]. In arteriovenous malformations (AVMs) shunting occurs through a network of vessels, the nidus. An arteriovenous fistula (AF) is defined as blood shunting through a single arterialized vein [65]. AVMs can arise anywhere in the body and therefore have a wide range of clinical manifestations. Symptoms can be described using the Schobinger staging system ( $\triangleright$ Table 2) [65]. Symptoms may include pulsatile masses, increased skin temperature, or palpable thrill. In advanced stages, patients develop venous hypertension, hemorrhage or tissue ischemia/necrosis close to the lesion. Large AVMs can be associated with congestive heart failure due to increased right cardiac preload. AVMs usually become progressively symptomatic over time, especially during puberty and pregnancy, and are prone to recurrence after therapy. Trauma and incomplete invasive therapy can cause an exacerbation of symptoms and increased proliferation.

AVMs may be associated with hereditary hemorrhagic telangiectasia (HHT) or Parkes Weber syndrome (PWS). Patients with HHT have multiple telangiectasias of the skin and mucosa, as well as multiple AVMs in the lungs, liver, or brain [66]. PWS should be suspected in patients with limb overgrowth, capillary malformation and arteriovenous malformation (as the predominant manifestation) [2].

AVMs are diagnosed primarily by ultrasound and MRI. Analysis of flow patterns is useful to establish the diagnosis of fast-flow malformations. Computed tomography (CT) can be performed in patients with pulmonary AVFs or in AVMs with bone involvement. Conventional arteriography is generally performed immediately before interventional treatment.

\section{Conservative therapy}

Compression garments can improve symptoms and quality of life. Management of chronic pain should be optimized by a specialist. At present, the use of mTOR inhibitors for the treatment of aggressive AVMs is less promising [18].

\section{Embolotherapy}

Invasive therapy is indicated in patients with progressive symptoms according to the Schobinger classification. Embolization as the therapy of first choice offers a way of treatment with low morbidity and acceptable results, but is prone to recurrence. In some cases preoperative embolization is an option when complete surgical resection of the nidus is achievable [22].

The goal of endovascular embolotherapy is to occlude the nidus or fistula completely. Commonly used agents are ethanol,
- Table 2 Schobinger clinical staging system for AVMs.

- Tab. 2 Schobinger-Klassifikation.

\begin{tabular}{|c|l|l|}
\hline stage & description & findings \\
\hline I & quiescence & cutaneous blush or warmth \\
\hline II & expansion & $\begin{array}{l}\text { bruit or thrill, increasing size, } \\
\text { pulsation, no pain }\end{array}$ \\
\hline III & local destruction & $\begin{array}{l}\text { pain, bleeding, infection, skin necrosis } \\
\text { or ulceration }\end{array}$ \\
\hline IV & decompensation & high-output cardiac failure \\
\hline
\end{tabular}

N-butyl cyanoacrylate (NBCA), ethylene-vinyl-alcohol-copolymer $(\mathrm{EVOH})$. Additionally, coils or vascular plugs are needed in some cases to optimize hemodynamics for further treatment, but those only occlude the feeding vessels and never reach the actual nidus. Therefore, their use is considered as adjuvant, and mere coiling of AMVs is obsolete nowadays. The interventionalist must be aware of the different delivery mechanisms and material properties. Many authors use a combination of the following embolic agents for the endovascular treatment of complex fast-flow malformations.

- Ethanol: If injected in the right manner, ethanol is a very potent embolic agent for the occlusion of symptomatic fast-flow malformations [67]. However, there is a high risk of tissue necrosis, nerve injury and systemic effects due to the immediate dislocation in the systemic circulation. Because of its low viscosity, ethanol passes the nidus very quickly into the lung circulation. Therefore, the pulmonary arterial pressure (PAP) should be monitored continuously during ethanol application. PAP above $25 \mathrm{mmHg}$ systolic can be found 10 to 15 minutes after application. To avoid side effects, most interventionalists administer less than $0.5 \mathrm{ml}$ per $\mathrm{kg}$ bodyweight in small aliquots.

- N-butyl cyanoacrylate (NBCA): N-butyl cyanoacrylate (NBCA) is a liquid adhesive agent that polymerizes irreversibly when exposed to blood. Therefore, the microcatheter has to be flushed with $40 \%$ glucose solution. To adjust polymerization time and to enable fluoroscopic visibility, NBCA is commonly mixed with lipiodol (ratio: 1:1 to 1:5). One major drawback of NBCA is the potential risk of catheter tip adhesion. As the liquid agent strictly follows the blood flow, it is rarely possible to occlude the complete nidus in large peripheral AVMs.

- Ethylene-vinyl-alcohol-copolymer (EVOH): EVOH is a nonadhesive liquid embolic agent mixed with dimethyl sulfoxide (DMSO) and radiopaque tantalum powder. Compared to NBCA, EVOH has a longer casting time, allowing further penetration into the nidus ( $\triangleright$ Fig. 5 ). It can be administered slowly in a controlled fashion under fluoroscopy, ideally using road map techniques ( $\triangleright$ Fig. 6) [68]. Using the reflux of EVOH as a plug around the catheter tip, an active forward push of EVOH into the whole nidus is possible even against the blood flow ("plug and push technique”, > Fig. 7). However, EVOH has 


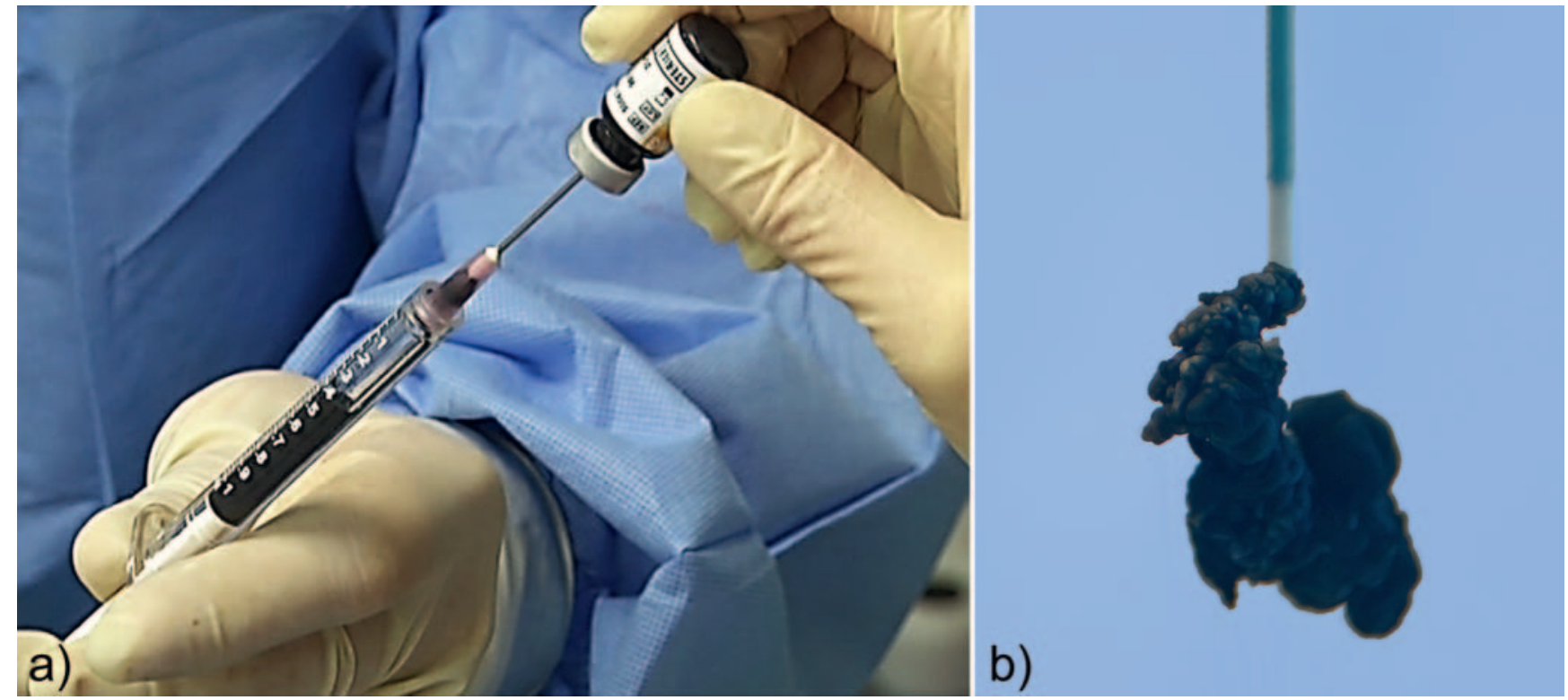

- Fig. 5 Ethylene-vinyl-alcohol-copolymer (EVOH). EVOH is a non-adhesive liquid embolic agent mixed with dimethyl sulfoxide (DMSO) and radiopaque tantalum powder.

- Abb.5 Ethylen-vinyl-alkohol-Kopolymer (EVOH). EVOH ist ein nichtadhäsives Flüssigembolisat gemischt mit Dimethylsulfoxid (DMSO) und röntgendichtem Tantal-Pulver.

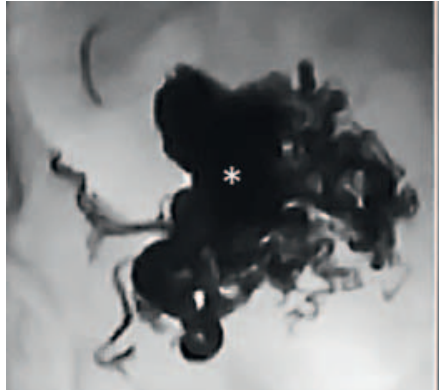

a)

- Fig. $6 \mathrm{EVOH}\left({ }^{*}\right)$ can be administered in a controlled manner under fluoroscopy. The distribution of EVOH can be followed easily using the "road map" technique (arrow).

- Abb. 6 EVOH (*) kann kontrolliert unter Durchleuchtung injiziert werden. Die Verteilung von EVOH kann mittels „road-map“ Technik entsprechend verfolgt werden (Pfeil).

some disadvantages. Injection is very painful and embolization should be performed under general anesthesia.

- Plugs and coils: Plugs and coils can be used in simple structured AVMs (type 1), for example in pulmonary fast-flow malformations. They also have a role as an embolic agent for outflow occlusion (type II lesions) [68].

Embolization technique: Baseline catheter-based diagnostic angiography should be performed to determine the flow characteristics and morphology of the malformation. AVMs can be classified into four types according to their angiographic pattern [67] ( $\triangleright$ Table 3). Most types of AVMs can initially be embolized via a transarterial approach. However, after occlusion of most feeding arteries, direct puncture often becomes necessary. In case of dominant venous outflow (type II), the nidus can be embolized using a retrograde transvenous embolization technique [68]. Direct puncture of the nidus is suitable in type II and IIIb lesions. Complete occlusion of the nidus should be achieved. Embolization of non-feeding parenchymal arteries must be avoided.

\section{Post-procedural care}

Post-procedural pain should be treated consequently often necessitating opioids to avoid stressful post-interventional recovery, which may prevent patients from a complete treatment series with multiple sessions. Close monitoring of the skin and neurovascular assessments are mandatory. After embolization, long-term clinical surveillance with intermittent imaging should be per- 


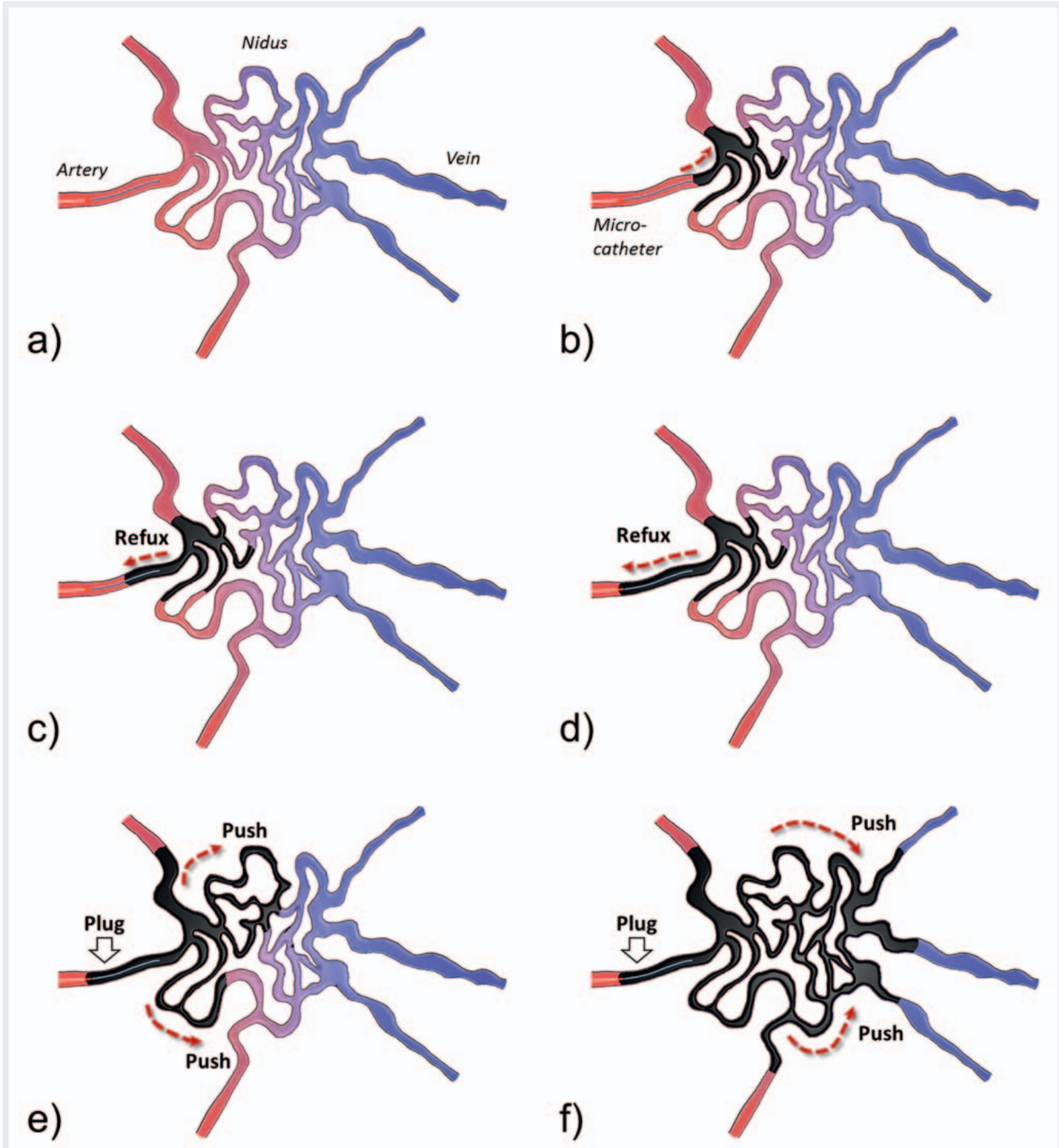

- Fig. 7 Plug and push technique. Using the reflux of EVOH as a plug around the detachable tip of the microcatheter, an active forward flow of $\mathrm{EVOH}$ into the whole nidus is possible regardless of the flow direction.

- Abb.7 Plug and Push Technik. Durch die Bildung eines Pfropfens EVOH um die ablösbare Katheterspitze ist es möglich EVOH unabhängig von der Blutflussrichtung in den Nidus zu pressen.

formed to rule out recurrence. Incomplete nidus embolization may stimulate aggressive growth.

\section{Conclusion}

Peripheral vascular malformations are rare but severe diseases that require a multidisciplinary approach. The radiologist plays a 
- Table 3 Angiographic classification of AVMs.

- Tab.3 Angiografische Klassifikation.

\begin{tabular}{|l|l|l|l|}
\hline type & morphology & description & $\begin{array}{l}\text { treatment } \\
\text { approaches }\end{array}$ \\
\hline $\mathbf{I}$ & $\begin{array}{l}\text { arteriove- } \\
\text { nous fistulae }\end{array}$ & $\begin{array}{l}\text { no more than } 3 \text { sepa- } \\
\text { rate arteries shunt to a } \\
\text { single venous compo- } \\
\text { nent }\end{array}$ & $\begin{array}{l}\text { transarterial } \\
\text { approach } \\
\text { direct puncture }\end{array}$ \\
\hline II & $\begin{array}{l}\text { arteriolove- } \\
\text { nous fistulae }\end{array}$ & $\begin{array}{l}\text { multiple arterioles } \\
\text { shunt into a single } \\
\text { venous component }\end{array}$ & $\begin{array}{l}\text { (transarterial } \\
\text { approach) } \\
\text { transvenous } \\
\text { approach } \\
\text { direct puncture }\end{array}$ \\
\hline IIla & $\begin{array}{l}\text { arteriolove- } \\
\text { nulous fistu- } \\
\text { lae without } \\
\text { dilatation }\end{array}$ & $\begin{array}{l}\text { multiple fine shunts } \\
\text { between arterioles and } \\
\text { venules (appear as a } \\
\text { blush or fine striation) }\end{array}$ & $\begin{array}{l}\text { transarterial } \\
\text { approach }\end{array}$ \\
\hline IIIb & $\begin{array}{l}\text { arteriolove- } \\
\text { nulous fistu- } \\
\text { lae with dila- } \\
\text { tation }\end{array}$ & $\begin{array}{l}\text { multiple dilated shunts } \\
\text { between arterioles } \\
\text { and venules (appear } \\
\text { as a complex vascular } \\
\text { network) }\end{array}$ & $\begin{array}{l}\text { transarterial } \\
\text { approach } \\
\text { direct puncture }\end{array}$ \\
\hline & & & \\
\hline
\end{tabular}

central role in the diagnosis and interventional management of these patients. Venous malformations and lymphatic malformations are predominantly treated by percutaneous sclerotherapy via a direct puncture. Fast-flow malformations are occluded with embolization via catheters or direct puncture. The interventionalist must be aware of the different materials and their properties. Treatment also includes knowledge about medical options, anticoagulation, and compression garments. It is self-evident that all this requires close communication between the patient, radiologist and other specialists.

\section{Conflict of Interest}

The authors declare that they have no conflict of interest.

\section{References}

[1] Mulliken JB, Glowacki J. Hemangiomas and vascular malformations in infants and children: a classification based on endothelial characteristics. Plast Reconstr Surg 1982; 69: 412-422

[2] Wassef M, Blei F, Adams D et al. Vascular Anomalies Classification: Recommendations From the International Society for the Study of Vascular Anomalies. Pediatrics 2015; 136: e203-e214

[3] Ahlawat S, Fayad LM, Durand D] et al. International Society for the Study of Vascular Anomalies Classification of Soft Tissue Vascular Anomalies: SurveyBased Assessment of Musculoskeletal Radiologists' Use in Clinical Practice. Curr Probl Diagn Radiol 2017. doi:10.1067/j.cpradiol.2017.10.003

[4] Horbach SER, Utami AM, Meijer-Jorna LB et al. Discrepancy between the clinical and histopathologic diagnosis of soft tissue vascular malformations. J Am Acad Dermatol 2017; 77: 920-929e1

[5] Gloviczki P, Driscoll D]. Klippel-Trenaunay syndrome: current management. Phlebology 2007; 22: 291-298
[6] Nozaki T, Nosaka S, Miyazaki O et al. Syndromes associated with vascular tumors and malformations: a pictorial review. Radiographics 2013; 33: $175-195$

[7] Dompmartin A, Acher A, Thibon P et al. Association of localized intravascular coagulopathy with venous malformations. Arch Dermatol 2008; 144: $873-877$

[8] Hung JW, Leung MW, Liu CS et al. Venous Malformation and Localized Intravascular Coagulopathy in Children. Eur J Pediatr Surg 2017; 27: $181-184$

[9] Mazoyer E, Enjolras O, Bisdorff A et al. Coagulation disorders in patients with venous malformation of the limbs and trunk: a case series of 118 patients. Arch Dermatol 2008; 144: 861 - 867

[10] Zhuo KY, Russell S, Wargon O et al. Localised intravascular coagulation complicating venous malformations in children: Associations and therapeutic options. J Paediatr Child Health 2017; 53: 737-741

[11] Enjolras O, Ciabrini D, Mazoyer E et al. Extensive pure venous malformations in the upper or lower limb: a review of 27 cases. J Am Acad Dermatol 1997; 36: 219-225

[12] Wohlgemuth WA, Muller-Wille R, Teusch $V$ et al. Ethanolgel sclerotherapy of venous malformations improves health-related quality-of-life in adults and children - results of a prospective study. Eur Radiol 2017; 27: $2482-2488$

[13] Fayad LM, Hazirolan T, Bluemke D et al. Vascular malformations in the extremities: emphasis on MR imaging features that guide treatment options. Skeletal Radiol 2006; 35: 127-137

[14] Hyodoh $\mathrm{H}$, Hori M, Akiba $\mathrm{H}$ et al. Peripheral vascular malformations: imaging, treatment approaches, and therapeutic issues. Radiographics 2005; 25 (Suppl. 1): S159-S171

[15] Sierre S, Teplisky D, Lipsich J. Vascular malformations: an update on imaging and management. Arch Argent Pediatr 2016; 114: 167-176

[16] Legiehn GM, Heran MK. A Step-by-Step Practical Approach to Imaging Diagnosis and Interventional Radiologic Therapy in Vascular Malformations. Semin Intervent Radiol 2010; 27: 209-231

[17] Kim D, Benjamin L, Wysong A et al. Treatment of complex periorbital venolymphatic malformation in a neonate with a combination therapy of sirolimus and prednisolone. Dermatol Ther 2015; 28: 218-221

[18] Triana P, Dore M, Cerezo VN et al. Sirolimus in the Treatment of Vascular Anomalies. Eur ] Pediatr Surg 2017; 27: 86 - 90

[19] Yesil S, Tanyildiz HG, Bozkurt C et al. Single-center experience with sirolimus therapy for vascular malformations. Pediatr Hematol Oncol 2016; 33: $219-225$

[20] Goldenberg DC, Carvas M, Adams D et al. Successful Treatment of a Complex Vascular Malformation With Sirolimus and Surgical Resection. J Pediatr Hematol Oncol 2017; 39: e191-e195

[21] Salloum R, Fox CE, Alvarez-Allende CR et al. Response of Blue Rubber Bleb Nevus Syndrome to Sirolimus Treatment. Pediatr Blood Cancer 2016; 63: $1911-1914$

[22] Ranieri M, Wohlgemuth W, Muller-Wille R et al. Vascular malformations of upper and lower extremity - from radiological interventional therapy to surgical soft tissue reconstruction - an interdisciplinary treatment. Clin Hemorheol Microcirc 2017; 67: 355 - 372. doi: 10.3233/CH-179216

[23] van der Vleuten C], Kater A, Wijnen MH et al. Effectiveness of sclerotherapy, surgery, and laser therapy in patients with venous malformations: a systematic review. Cardiovasc Intervent Radiol 2014; 37: $977-$ 989

[24] Green D. Mechanism of action of sclerotherapy. Semin Dermatol 1993; 12: $88-97$

[25] Horbach SE, Lokhorst MM, Saeed P et al. Sclerotherapy for low-flow vascular malformations of the head and neck: A systematic review of sclerosing agents. J Plast Reconstr Aesthet Surg 2016; 69: 295 - 304

[26] Qiu Y, Chen H, Lin X et al. Outcomes and complications of sclerotherapy for venous malformations. Vasc Endovascular Surg 2013; 47: 454 - 461 
[27] Ali S, Mitchell SE. Outcomes of Venous Malformation Sclerotherapy: A Review of Study Methodology and Long-Term Results. Semin Intervent Radiol 2017; 34: 288-293

[28] Steiner F, Fitz]ohn T, Tan ST. Ethanol sclerotherapy for venous malformation. ANZ J Surg 2016; 86: 790 -795

[29] Ali S, Weiss CR, Sinha A et al. The treatment of venous malformations with percutaneous sclerotherapy at a single academic medical center. Phlebology 2016; 31: $603-609$

[30] Orlando JL, Caldas JG, Campos HG et al. Ethanol sclerotherapy of head and neck venous malformations. Einstein (Sao Paulo) 2014; 12: 181 - 186

[31] Gurgacz S, Zamora L, Scott NA. Percutaneous sclerotherapy for vascular malformations: a systematic review. Ann Vasc Surg 2014; 28: 1335 1349

[32] Zhang J, Li HB, Zhou SY et al. Comparison between absolute ethanol and bleomycin for the treatment of venous malformation in children. Exp Ther Med 2013; 6: 305-309

[33] Hu X, Chen D, Jiang C et al. Retrospective analysis of facial paralysis caused by ethanol sclerotherapy for facial venous malformation. Head Neck 2011; 33: 1616-1621

[34] Orlando JL, Caldas JG, Campos HG et al. Outpatient percutaneous treatment of deep venous malformations using pure ethanol at low doses under local anesthesia. Clinics (Sao Paulo) 2010; 65: 837 - 840

[35] Spence J, Krings T, TerBrugge KG et al. Percutaneous treatment of facial venous malformations: a matched comparison of alcohol and bleomycin sclerotherapy. Head Neck 2011; 33: 125 -130

[36] Bisdorff A, Mazighi M, Saint-Maurice JP et al. Ethanol threshold doses for systemic complications during sclerotherapy of superficial venous malformations: a retrospective study. Neuroradiology 2011; 53: 891 - 894

[37] Schumacher M, Dupuy P, Bartoli JM et al. Treatment of venous malformations: first experience with a new sclerosing agent-a multicenter study. Eur J Radiol 2011; 80: e366-e372

[38] Teusch VI, Wohlgemuth WA, Hammer S et al. Ethanol-Gel Sclerotherapy of Venous Malformations: Effectiveness and Safety. Am J Roentgenol 2017; 209: 1390 - 1395. doi:10.2214/AJR.16.17603

[39] Sannier K, Dompmartin A, Theron J et al. A new sclerosing agent in the treatment of venous malformations. Study on 23 cases. Interv Neuroradiol 2004; 10: 113-127

[40] Dompmartin A, Blaizot X, Theron J et al. Radio-opaque ethylcelluloseethanol is a safe and efficient sclerosing agent for venous malformations. Eur Radiol 2011; 21: 2647 - 2656

[41] Weitz-Tuoretmaa A, Keski-Nisula L, Rautio R et al. Quality of life after endovascular sclerotherapy of low-flow venous malformations: the efficacy of polidocanol compared with ethanol. Acta Radiol 2017. doi: $10.1177 / 0284185117741774$

[42] Cabrera J, Cabrera J Jr, Garcia-Olmedo MA. Sclerosants in microfoam. A new approach in angiology. Int Angiol 2001; 20: 322 - 329

[43] Cabrera J, Cabrera J Jr, Garcia-Olmedo MA et al. Treatment of venous malformations with sclerosant in microfoam form. Arch Dermatol 2003; 139: $1409-1416$

[44] Tessari L, Cavezzi A, Frullini A. Preliminary experience with a new sclerosing foam in the treatment of varicose veins. Dermatol Surg 2001; 27 : $58-60$

[45] Yamaki T, Nozaki M, Sakurai H et al. Prospective randomized efficacy of ultrasound-guided foam sclerotherapy compared with ultrasound-guided liquid sclerotherapy in the treatment of symptomatic venous malformations. J Vasc Surg 2008; 47: 578-584

[46] Park HS, Do YS, Park KB et al. Clinical outcome and predictors of treatment response in foam sodium tetradecyl sulfate sclerotherapy of venous malformations. Eur Radiol 2016; 26: 1301 - 1310

[47] Alakailly X, Kummoona R, Quereshy FA et al. The use of sodium tetradecyl sulphate for the treatment of venous malformations of the head and neck. J Maxillofac Oral Surg 2015; 14: 332 - 338
[48] Songsaeng D, Churojana A, Khumthong R et al. Comparative outcomes for sclerotherapy of head and neck venous vascular malformation between alcohol and bleomycin. J Med Assoc Thai 2015; 98: 408-413

[49] Puig S, Aref H, Chigot V et al. Classification of venous malformations in children and implications for sclerotherapy. Pediatr Radiol 2003; 33: $99-103$

[50] Burrows PE, Mason KP. Percutaneous treatment of low flow vascular malformations. J Vasc Interv Radiol 2004; 15: 431 - 445

[51] Patel PA, Barnacle AM, Stuart S et al. Endovenous laser ablation therapy in children: applications and outcomes. Pediatr Radiol 2017; 47: 1353 1363

[52] Berber O, Holt P, Hinchliffe R et al. Endovenous therapy for the treatment of congenital venous malformations. Ann Vasc Surg 2010; 24: 415 e13-417

[53] Alomari Al, Karian VE, Lord D] et al. Percutaneous sclerotherapy for lymphatic malformations: a retrospective analysis of patient-evaluated improvement. J Vasc Interv Radiol 2006; 17: 1639-1648

[54] Strychowsky JE, Rahbar R, O’Hare M] et al. Sirolimus as treatment for 19 patients with refractory cervicofacial lymphatic malformation. Laryngoscope 2017. doi:10.1002/lary.26780

[55] Lackner H, Karastaneva A, Schwinger W et al. Sirolimus for the treatment of children with various complicated vascular anomalies. Eur ] Pediatr 2015; 174: 1579-1584

[56] Thomas DM, Wieck MM, Grant CN et al. Doxycycline Sclerotherapy Is Superior in the Treatment of Pediatric Lymphatic Malformations. J Vasc Interv Radiol 2016; 27: 1846-1856

[57] Rebuffini E, Zuccarino L, Grecchi E et al. Picibanil (OK-432) in the treatment of head and neck lymphangiomas in children. Dent Res J (Isfahan) 2012; 9 (Suppl. 2): S192-S196

[58] Motz KM, Nickley KB, Bedwell JR et al. OK432 versus doxycycline for treatment of macrocystic lymphatic malformations. Ann Otol Rhinol Laryngol 2014; 123: $81-88$

[59] Ravindranathan H, Gillis ], Lord D]. Intensive care experience with sclerotherapy for cervicofacial lymphatic malformations. Pediatr Crit Care Med 2008; 9: 304 - 309

[60] Yura J, Hashimoto T, Tsuruga N et al. Bleomycin treatment for cystic hygroma in children. Nihon Geka Hokan 1977; 46: 607-614

[61] Yang Y, Sun M, Ma Q et al. Bleomycin A5 sclerotherapy for cervicofacial lymphatic malformations. J Vasc Surg 2011; 53: 150-155

[62] Cheng J. Doxycycline sclerotherapy in children with head and neck lymphatic malformations. J Pediatr Surg 2015; 50: 2143-2146

[63] Shergill A, John P, Amaral JG. Doxycycline sclerotherapy in children with lymphatic malformations: outcomes, complications and clinical efficacy. Pediatr Radiol 2012; 42: 1080 - 1088

[64] Burrows PE, Mitri RK, Alomari A et al. Percutaneous sclerotherapy of lymphatic malformations with doxycycline. Lymphat Res Biol 2008; 6: $209-216$

[65] Dunham GM, Ingraham CR, Maki JH et al. Finding the Nidus: Detection and Workup of Non-Central Nervous System Arteriovenous Malformations. Radiographics 2016; 36: 891 - 903

[66] Grigg C, Anderson D, Earnshaw ]. Diagnosis and Treatment of Hereditary Hemorrhagic Telangiectasia. Ochsner ] 2017; 17: 157 - 161

[67] Cho SK, Do YS, Shin SW et al. Arteriovenous malformations of the body and extremities: analysis of therapeutic outcomes and approaches according to a modified angiographic classification. J Endovasc Ther 2006; 13: $527-538$

[68] Wohlgemuth WA, Muller-Wille R, Teusch VI et al. The retrograde transvenous push-through method: a novel treatment of peripheral arteriovenous malformations with dominant venous outflow. Cardiovasc Intervent Radiol 2015; 38: 623-631 